\title{
Article
}

\section{Rationale for the Combined Use of Biological Processes and AOPs in Wastewater Treatment Tasks}

\author{
Vladimir Shtepa ${ }^{1,2}$, Magdalena Balintova ${ }^{2,3, *(\mathbb{D})}$, Yelizaveta Chernysh ${ }^{2,4}$ (D), Viktoriia Chubur ${ }^{4}$, Stefan Demcak ${ }^{2}$ (D) \\ and Mathieu Gautier 2,5
}

1 Faculty of Engineering, Polessky State University, 23, Dneprovskoy Flotilii Street, 225710 Pinsk, Belarus; shtepa.v@polessu.by

2 International Innovation and Applied Center "Aquatic Artery", Sumy State University, 2, Rymskogo-Korsakova Street, 40007 Sumy, Ukraine; e.chernish@ssu.edu.ua (Y.C.); demcak.stefan@gmail.com (S.D.); mathieu.gautier@insa-lyon.fr (M.G.)

3 Institute of Environmental Engineering, Faculty of Civil Engineering, Technical University of Kosice, Vysokoskolska 4, 04200 Kosice, Slovakia

4 Department of Ecology and Environmental Protection Technologies, Faculty of Technical Systems and Energy Efficient Technologies, Sumy State University, 2, Rymskogo-Korsakova Street, 40007 Sumy, Ukraine; v.chubur@ecolog.sumdu.edu.ua

5 University Lyon, INSA Lyon, DEEP, EA7429, 69621 Villeurbanne, France

* Correspondence: magdalena.balintova@tuke.sk; Tel.: +421-155-602-4127

Citation: Shtepa, V.; Balintova, M.; Chernysh, Y.; Chubur, V.; Demcak, S.; Gautier, M. Rationale for the Combined Use of Biological Processes and AOPs in Wastewater Treatment Tasks. Appl. Sci. 2021, 11, 7551. https://doi.org/10.3390/app11167551

Academic Editor: Juan García Rodríguez

Received: 13 July 2021

Accepted: 11 August 2021

Published: 17 August 2021

Publisher's Note: MDPI stays neutral with regard to jurisdictional claims in published maps and institutional affiliations.

Copyright: (c) 2021 by the authors Licensee MDPI, Basel, Switzerland. This article is an open access article distributed under the terms and conditions of the Creative Commons Attribution (CC BY) license (https:// creativecommons.org/licenses/by/ $4.0 /)$.

\begin{abstract}
This paper aims to form a unified concept of the integrated use of different wastewater treatment methods to form a resistant biological treatment stage of technological systems under the influence of such toxic factors as antibiotics and surfactants. The processes of mechanical treatment, ozonation, UV irradiation, and electrolytic anodic oxidation were implemented in an electrotechnological wastewater treatment facility. Wastewater treatment quality was determined by the concentration of nitrogen compounds in aqueous solutions according to the method of Lurie. Biodiagnostics of the investigated activated sludge via surfactant action was carried out at polyethylene oxide concentrations of 10,30 , and $50 \mathrm{mg} / \mathrm{dm}^{3}$. As a result of experiments on wastewater treatment after aquaculture, an improvement in the reduction of pollutants only by the indicator "nitrate concentration" was determined: by $20 \%$ after anodic oxidation, and by $15 \%$ after photolysis. At almost all surfactant concentrations studied, the activated sludge was not completely recovered, which was expressed in a decrease in its quantity and in the inability to aggregate flakes of activated sludge. The diameter of the growth retardation of the standard disk with antibiotic (amoxiclav) by the accumulative culture of activated sludge was $17.3 \pm 2 \mathrm{~mm}$ at a concentration of $4 \mathrm{mg} / \mathrm{dm}^{3}$ and $31.3 \pm 3 \mathrm{~mm}$ at a concentration of $6 \mathrm{mg} / \mathrm{dm}^{3}$. In the process of studying the state of the activated sludge's biocenosis under the influence of such toxicants, several regularities were revealed. The directions of using combined approaches of water treatment and wastewater treatment were defined. The structural model of treatment facilities using aerobic and anaerobic bioprocesses together with advanced oxidative technologies was substantiated.
\end{abstract}

Keywords: combined wastewater treatment; aerobic and anaerobic bioprocesses; advanced oxidative technologies; toxicants; combined approaches

\section{Introduction}

The introduction of various types of toxicants-in particular, antibiotics and surfactants-into aquatic ecosystems is becoming an increasing problem. For example, a global problem in the conservation of aquatic ecosystems is the active pollution of water resources worldwide with pharmaceutical products, including antibiotics, whose concentration in some rivers of the world exceeds the safety limit [1,2].

As noted in studies, up to $90 \%$ of antibiotics used will end up in components of the natural environment, such as soil and water bodies. Medicinal drug residues enter rivers 
from human and animal waste, as well as from suboptimal treatment facilities, including those of pharmaceutical companies [3,4]. Additionally, antibiotics can significantly change the biocenosis of water bodies [3].

The predominant contribution to the pollution of natural objects with non-ionic and cationic surfactants is made by industrial enterprises and their auxiliary structures. The latter use surfactants as high-molecular-weight flocculants in the pretreatment of wastewater and clarification of sludge. In addition, surfactants are widely used as active ingredients in detergents and cleaning agents, as well as in a wide range of applications such as paints, pesticide formulations, pharmaceuticals, moisturizers, and personal care products [1,5]. They can be divided into four main groups according to their charge: anionic, nonionic, cationic, and amphoteric. Despite their relatively high solubility, these compounds have moderate-to-high sorption capacity, and several intermediates are formed during their degradation [5].

Given the high probability of some of the high-molecular-weight reagents entering the biological treatment unit, there is a need to investigate their effects on the activated sludge's biocenosis in order to study the possible effects on the biological treatment process of the wastewater. Surfactants destroy activated sludge flocs and disrupt the oxygen regime; as such, we should expect significant destruction of zoogloea and the appearance of freefloating cells, which leads to steady turbidity of the nadir fluid, as well as an intensive damaging effect on hydrobionts, as confirmed by previous studies [4-6].

At the same time, in recent decades, wastewater and drinking water treatment technologies have undergone rapid development. Wastewater treatment methods are divided into four basic groups [7,8]:

- Mechanical methods are generally the cheapest, and are used for the separation of suspended solids in the preliminary stage of water treatment;

- Chemical methods are classically used to remove inorganic impurities from wastewater. When treated with reagents, dissolved compounds are neutralized, and decolorization and disinfection take place;

- Physicochemical methods are mainly used for the removal of coarse and fine dispersed particles, as well as the neutralization of colloidal impurities and dissolved compounds;

- Biological methods of wastewater treatment are used to remove organic compounds from wastewater. They use the ability of microorganisms to decompose organic compounds.

It should be noted that in order to obtain high efficiency of water treatment at real facilities, combined installations are used, including several known methods of impact on water solutions [9]. At the same time, there is a need to implement comprehensive solutions for intensification of purification at volley releases of toxic substances, such as antibiotics and surfactants, since these toxicants are widely used in human activities and their entry has a negative impact on the operation of sewage treatment plants in both individual enterprises and municipalities. This reduces the efficiency of wastewater treatment systems, and also suppresses the metabolic activity of various ecologo-trophic groups involved in the biological phase of treatment.

Considering the distribution of the proportion of publications on wastewater treatment topics (Figure 1), there has been an increase in publication activity in this area since 1970, with an intensive build-up of research on various areas of wastewater treatment beginning in 2005. The rapid growth of publication activity began in 2016, and peaked in 2020. 


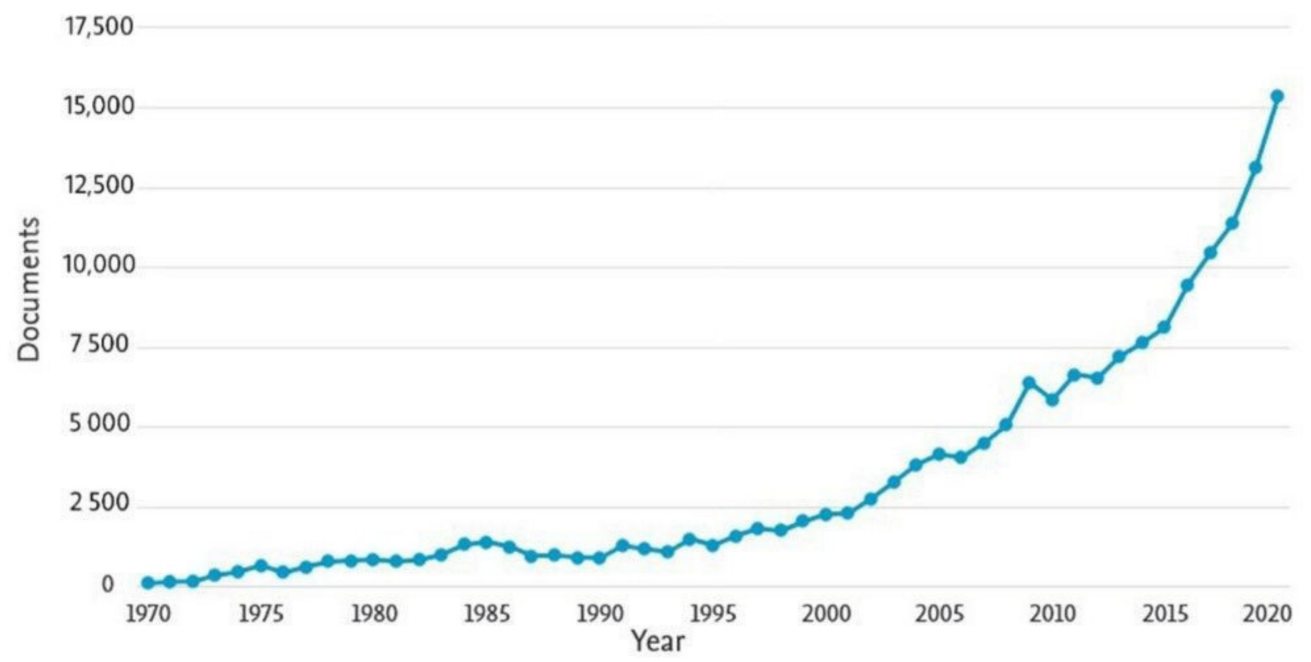

Figure 1. Publication activity curve by year based on the Scopus database using the keyword combination "wastewater" and "treatment".

In recent decades, there has been a clear trend towards the mainstreaming of water conservation issues in different regions of the world, with the formation of a number of integrated solutions for treatment of wastewater of different origins $[10,11]$. Thus, Figure 2 shows the thematic area of research according to different sources of publications, showing that there is an interdisciplinary approach to the topic of wastewater treatment. Publications in engineering, chemical sciences, and ecology, as well as materials science and energy, predominate. At the interface of the sciences, there is also interaction with the trend of engineering implementation of solutions for wastewater management and treatment of sewage sludge, development of sustainable water management and its energy potential, and environmental and economic justification of wastewater treatment processes. At the same time, biological processes for wastewater and sludge treatment have been widely used [12,13].

Special attention is given to the processes of studying the inhibitory effects of various toxic substances on the bioprocess of wastewater treatment [14]. For example, Qiu et al. [14] investigated the modes of operation of a hybrid membrane bioreactor with directed osmosis microfiltration (MF-FOMBR) in the treatment of municipal wastewater. The effects of 20 commonly used antibiotics were investigated. At concentrations of 4.1-716.9 ng/L (regrafloxacin, sulfamethazine, and cephalexin were the most common antibiotics, followed by amoxicillin, lomefloxacin, and ampicillin), the system showed total removal of 58.9$100 \%$ of all antibiotics [14]. However, it is worth noting the wide range in the removal efficiency of these antibiotics, which indicates the different levels of resistance to them of the activated sludge's biocenosis.

A study by Shi et al. [15] operated aerobic granular sludge (AGS) at high ammonium concentration to remove three fluoroquinolones (FQs), i.e., ciprofloxacin, ofloxacin, and norfloxacin at 3, 300, and $900 \mu \mathrm{g} / \mathrm{L}$, respectively. The main objectives were to study the differential distribution of antibiotic resistance genes and mobile genetic elements in the sludge fractions in the nitrification and denitrification processes. AGS demonstrated excellent stability under the influence of FQs, with nitrite-oxidizing bacteria being more sensitive to FQs than ammonium-oxidizing bacteria [15]. Thus, it was determined that different ecological and trophic levels of the biocenosis have their own threshold of adaptation to increasing concentrations of antibiotics, which is also important to consider when optimizing the wastewater treatment process. 


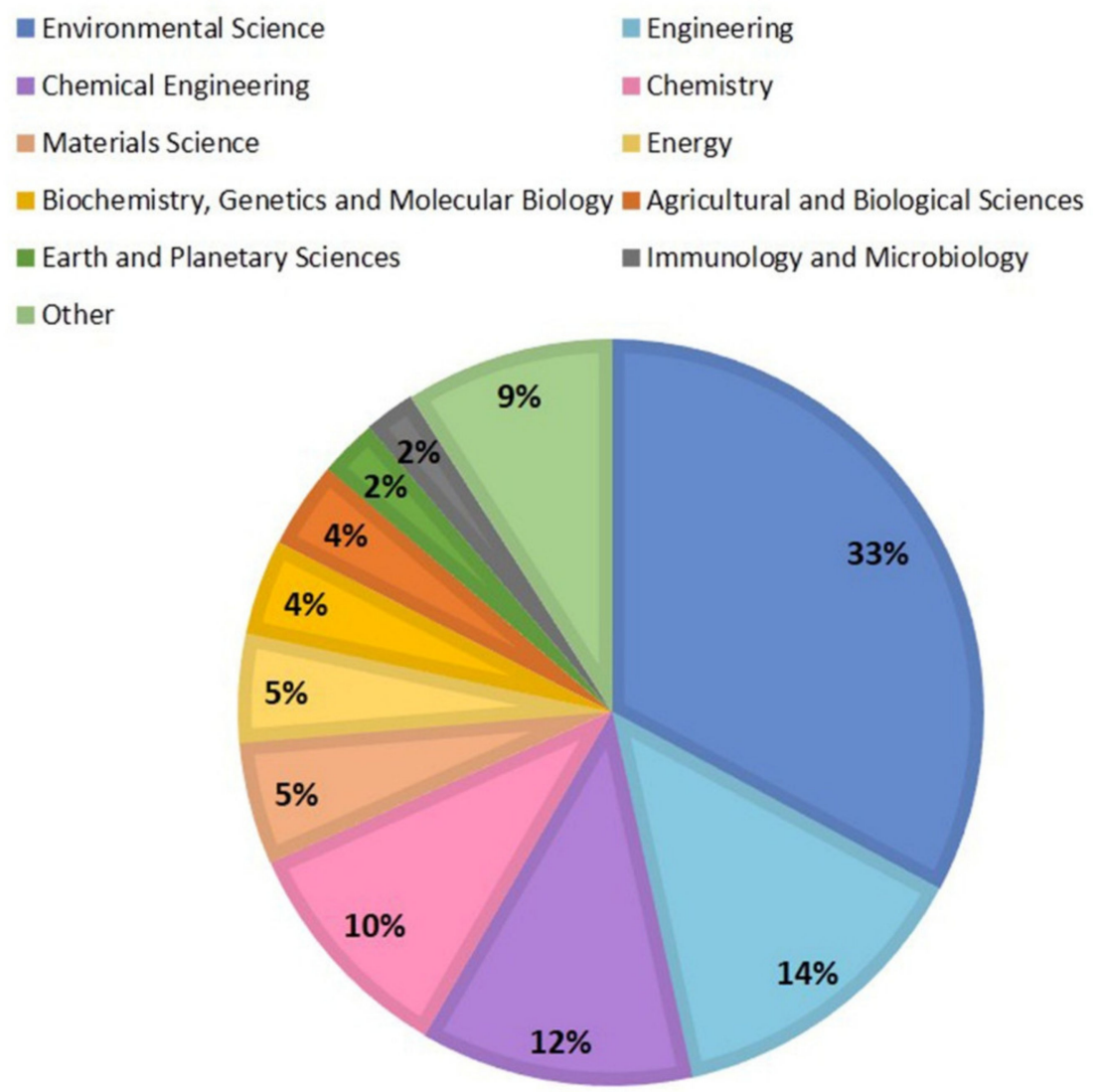

Figure 2. Thematic areas of publications in the field of wastewater treatment according to the Scopus database.

A study by Zhu et al. [16] described the effects of antibiotics and antibiotic-resistance genes in biological treatment technologies and combined processes in wastewater treatment plants. Adsorption is the main antibiotic removal mechanism for tetracyclines, fluoroquinolones, and macrolides, while biodegradation is the pathway for antibiotic removal for sulfonamides and $\beta$-lactams. In addition, the process of microbial co-metabolism contributes to the biodegradation of antibiotics. Process engineering and continuous monitoring and control of bioremediation parameters, the flexibility of the system to adapt to fluctuations, and capital and operating costs are all important [16].

Microbial community biodiversity is shaped by many coexisting factors, including seasonality, the material of water system fixtures and biofilm carriers, and the location of sampling sites. Spatial distribution analysis showed that samples collected from the same sampling locations were similar to each other in terms of antibiotic resistance and biodiversity; this indicates that antibiotic resistance spreads locally over small distances in biofilm [17].

A study by Shi et al. [18] proposed an electrodialysis (ED) system, named ED anode, which can be used in situ for the electrochemical removal of antibiotics during nutrient ( $\mathrm{N}$ and $\mathrm{P}$ ) recovery from animal manure digestate, which requires further research in order to optimize the system's mode of operation under different environmental conditions [18].

In a study by Corada-Fernandez et al. [3], the distribution of anionic and nonionic surfactants was studied in groundwater in the UH 05.56 hydrologic unit (Spain). Surfactant concentrations ranging from 1.1 to $9.7 \mu \mathrm{g} / \mathrm{L}$ were detected, with the highest concentrations detected in 3 of the 10 wells sampled. The aquifer was dominated by oxic conditions and $\mathrm{pH}$ ranges from 6.5 to 9 . The presence of surfactants was the result of agricultural irrigation with water from the river mixed with treated wastewater. It is worth noting that surfactants are currently used in pesticides, so their presence is also due to agricultural management [3]. 
A study by Kruszelnicka et al. [19] focused on evaluating the performance of two types of domestic wastewater treatment plant: a wetland wastewater treatment plant (ORS type), and an SBR-type wastewater treatment plant (SBR-K-6 type). At the ORS- and SBR-K-6type wastewater treatment plants, the anionic surfactants were removed up to 98 and $88 \%$, respectively. A lower removal efficiency was achieved in the case of non-ionic surfactants, which reached $76 \%$ for the ORS-type facility and $56 \%$ for the SBR-K-6-type facility; this demonstrates the need for comprehensive solutions that address the technological mode of operation of treatment plants [19].

Despite numerous publications on the problems associated with proper management of this type of wastewater treatment plant, none of the studies take into account the operating conditions of activated sludge and, in particular, the effects of surfactants on activated sludge. The evaluative analysis conducted shows that the treatment and daily care of surfactant concentrations in wastewater can harm the performance of domestic wastewater treatment. It is very important that these products can be used in care after the dilution recommended by the manufacturers. Research has also shown that sludge is highly resistant to single doses of wastewater with high concentrations of anionic surfactants [20]. However, such concentrations should not be routinely fed into domestic wastewater, due to limited activated sludge capacity and limited adsorption of biodegradable surfactants. It is also recommended to periodically check the content of anionic surfactants in treated domestic wastewater, due to their negative effects on soil and vegetation [20].

A separate direction has been the use of advanced oxidation processes (AOPs) [21] for wastewater treatment tasks, which include several advanced technological solutions, such as homogeneous and heterogeneous photocatalytic processes, ozonation, variants of the Fenton process, ultrasonic treatment, wet oxidation, oxidation in supercritical water, plasma processes, ferrate and persulfate technologies, use of ionizing radiation, and microwave treatment.

The use of Fenton's reagent when irradiating the aqueous solution with ultraviolet light (wavelength $254 \mathrm{~nm}$ ) and controlling the $\mathrm{pH}$ values allows for deep destruction of organic pollutants, with an efficiency of more than $80 \%$ [22].

The combination of ultraviolet irradiation (wavelength $254 \mathrm{~nm}$ ) and the application of hydrogen peroxide $\left(\mathrm{H}_{2} \mathrm{O}_{2}\right)$, in addition to the oxidation of contaminants, enhances the complex effect of disinfection of the treated medium by at least 20-fold [23].

The use of a strong oxidizing agent such as ferrates (VI) — which are among the most powerful existing oxidizers and, due to their action, decompose many toxic chemicals into low-toxicity products, as well as causing the death of microorganisms due to their disinfecting action—should be singled out separately. In an acidic environment, the potential of $\mathrm{FeO}_{4}{ }^{2-}$ ions is higher than that of ozone, and is the highest among the currently used compounds [24]. At the same time, even the AOP technologies used must be an integration of two or more processes. Furthermore, nanotechnology can be applied in wastewater separation, bioremediation, and disinfection [25]. Wu et al. studied vacuum filtering and mixed-polymer e-spinning membranes made from Fe-containing nanomaterials to remove $\mathrm{Cd}^{2+}$ ions from neutral aqueous solution [26].

In a study by Saaremäe et al., Ca-Fe oxide pellets were studied as a potential sorption material for established wetlands. However, the weaknesses of this material for sorption filter systems were noted: mass loss caused by rapid dissolution of gypsum, increased sulfate and calcium concentrations in the water, and rapidly changing hydraulic conductivity [27].

In a study by Muszyński et al., wastewater from a cosmetic factory was treated with a combined light $/ \mathrm{Fe}^{0} / \mathrm{H}_{2} \mathrm{O}_{2}$ process, followed by biological treatment. The light $/ \mathrm{Fe}^{0} / \mathrm{H}_{2} \mathrm{O}_{2}$ process with doses of $1000 / 2280 \mathrm{mg} / \mathrm{L} \mathrm{Fe}^{0} / \mathrm{H}_{2} \mathrm{O}_{2}$ and a process time of 120 min resulted in $70 \%$ removal of COD. The chemically treated wastewater was subjected to biological treatment, resulting in an overall COD removal of up to $97.7 \%$. Untreated cosmetic wastewater subjected to biological treatment caused serious changes in the microbial community structure, resulting in a significant decrease in the removal efficiency of organic 
carbon, nitrogen, and phosphorus [28]. The results indicate the feasibility of further research on the combination of AOP processes with bioremediation.

Thus, the problem of wastewater treatment must be considered comprehensively, combining different technological solutions with a combination of treatment methods to achieve the most sustainable operation of treatment plants.

This study aims to form a unified concept of the integrated use of different methods of wastewater treatment to form a stable technological system under the influence of toxic factors such as the intake of antibiotics and surfactants.

The set objectives of the study are:

- To study the wastewater treatment of closed-loop water supply installations (CLWSI) from nitrogen compounds using AOPs;

- To research the effects of antibiotics and surfactants on the activity of biological processes;

- To develop an integrated model for combining biological processes and AOPs in wastewater treatment.

\section{Materials and Methods}

\subsection{Experimental Electrotechnological Water Treatment Complex}

To treat the water solution of the closed-loop water supply plant for the cultivation of hydrobionts, the parallel AOP module was connected to the existing industrial equipment (Figure 3).

Water supplied to compensate for its losses in technological processes

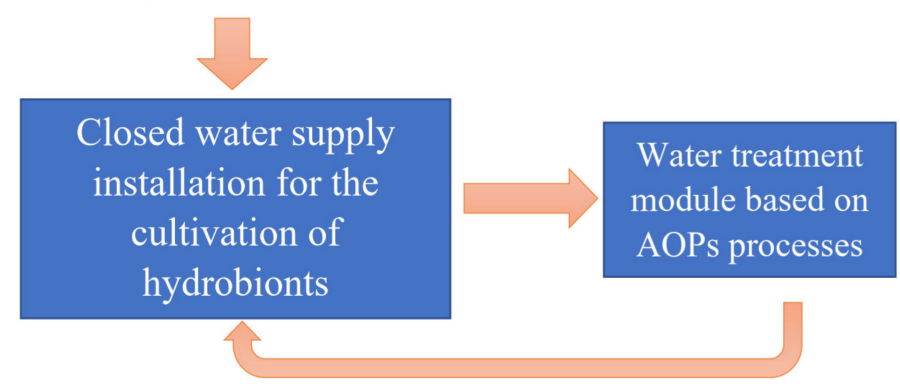

Figure 3. Scheme of connection of the AOP module to a closed-loop water supply system for the cultivation of hydrobionts.

The processes of mechanical purification (filter sieve and laminar settling tank), ozonation, UV irradiation, and electrolytic anodic oxidation were implemented in the electrotechnological water treatment complex (Figure 4).

The stages of experimental flow-through treatment were as follows (Figure 4):

- Mechanical separation of pollutants (filter sieve and laminar settling tank);

- Water supply to the electrolysis unit for anodic oxidation of pollutants;

- Ozone supply to the reactor-mixer to implement the photolysis process (synergistic oxidative process of ozone and ultraviolet irradiation);

- Analysis of quality indicators of water solution by the concentration of nitrogen compounds (i.e., ammoniacal nitrogen, nitrites, nitrates). 


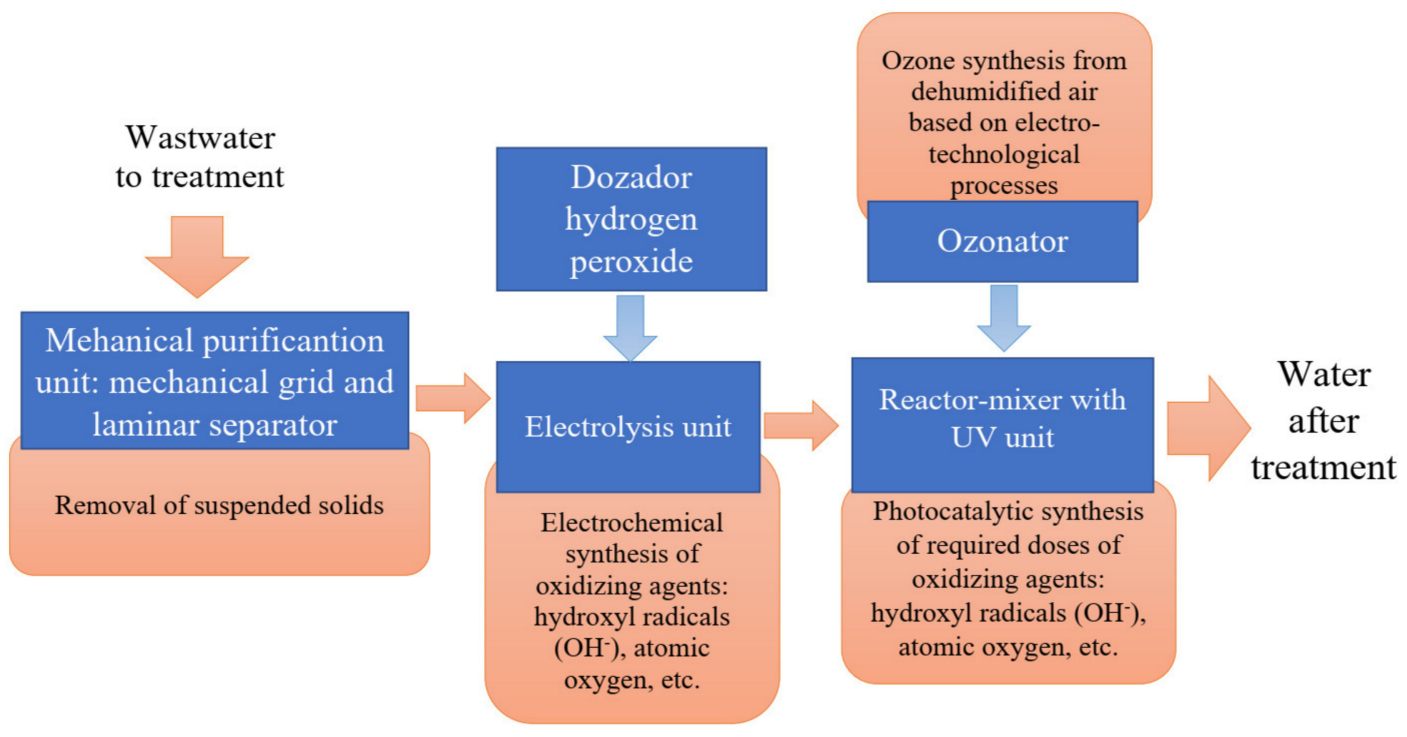

Figure 4. The structural diagram of the electrotechnological water treatment complex using AOPs (ozonation, UV irradiation, and electrolytic anodic oxidation).

To ensure the course of electrolysis processes, a diaphragm electrolyzer with an inactive membrane (anode and cathode were made of electrode graphite; in the anode were additional poured shavings), a volume of $3 \mathrm{~L}$ at a current strength of $10 \mathrm{~A}$ was used; electrolysis time was $120 \mathrm{~s}$.

The ozonator provided ozone generation with a production capacity of $6 \mathrm{~g} / \mathrm{h}$. The UV-irradiation unit operated at a "germicidal" wave with a frequency of $245 \mathrm{~nm}$, a power of 55 watts, and a photolysis treatment time of $20 \mathrm{~min}$.

Water treatment quality was determined by the concentration of nitrogen compounds in aqueous solutions according to Lurie's methodology [29].

Two types of CLWSI circulating water were treated:

- $\quad$ Type 1: Aqueous solution $14 \mathrm{~h}$ after feeding the fish and 8-fold turnover through a filter sieve and laminar sump: characterized by translucency of $87.3 \%$; no fat stains;

- $\quad$ Type 2: Aqueous solution $2 \mathrm{~h}$ after feeding the fish and 1-time turnover through a filter sieve and laminar sump: characterized by translucency of $72.4 \%$, with significant fat stains caused by residual feed and a yellowish hue caused by the presence of organic colloidal particles.

\subsection{Methods of Microbiological Research of the Effects of Antibiotics and Surfactants on the Biocenosis of Activated Sludge}

The activated sludge was taken from the operating treatment facilities of the MHP "Orel-Leader", which is the largest integrated poultry farm in the Dnepropetrovsk region. In 2012, it commissioned an anaerobic digester in the village of Elizavetovka, which produces 20 million $\mathrm{m}^{3}$ of biogas annually, from which it continuously produces 5 megawatt hours of electricity, as well as 119,000 million BTU of recovered heat.

To Study the resistance of activated sludge biocenosis to antibiotics, we used the agar diffusion method to determine the sensitivity of the activated sludge's biocenosis to a widespread group of antibiotics [30].

Nutrient medium was prepared on nutrient agar. The nutrient agar (manufacturer LLC "Farmaktiv", Kyiv, Ukraine) was composed of enzymatic peptone $\left(10 \mathrm{~g} / \mathrm{dm}^{3}\right)$, microbial agar $\left(10 \mathrm{~g} / \mathrm{dm}^{3}\right)$, sodium chloride $\left(5 \mathrm{~g} / \mathrm{dm}^{3}\right)$, and yeast extract $\left(2.53 \mathrm{~g} / \mathrm{dm}^{3}\right)$.

The stages of using nutrient agar were:

1. Dissolve $28 \mathrm{~g}$ of the medium by heating in $1 \mathrm{~L}$ of purified water;

2. Boil for 2-3 min until all components are dissolved;

3. Autoclave for $15 \mathrm{~min}$ at $121^{\circ} \mathrm{C}$; 
4. Cool to $45^{\circ} \mathrm{C}$ and pour into sterile Petri dishes.

$\mathrm{pH}$ was maintained at $7.3 \pm 0.2$ under $25^{\circ} \mathrm{C}$.

The seeding was performed by looping (stroking seeding) according to Gold's method. On the outer side of the bottom of the Petri dish, we drew delimiting lines with nutrient agar, dividing it into 4 sectors. The analyzed activated sludge was introduced with a loop into the first sector, drawing parallel lines across the whole sector at a distance of about $5 \mathrm{~mm}$ from one another. The same loop, without changing its position concerning the nutrient medium, drew the same lines on other sectors of the cup.

Incubation of antibiotics with activated sludge was carried out for $96 \mathrm{~h}$ at $25^{\circ} \mathrm{C}$. Six repeated tests were performed to obtain reliable results.

The technique of visual assessment by the diameter of the culture growth retardation zones was used, indicating its sensitivity to the appropriate antibiotics (Table 1).

Table 1. Interpretation criteria for the sensitivity of microorganisms of the storage culture of activated sludge.

\begin{tabular}{ccc}
\hline Microbial Sensitivity Category & $\begin{array}{c}\text { Growth } \\
\text { Retardation, } \mathbf{~ m m}\end{array}$ & Microbiological Characteristics \\
\hline Sensitive (S-susceptible) & $\leq 4$ & Does not have resistance mechanisms \\
Intermediately resistant or moderately & $14-18$ & $\begin{array}{c}\text { Subpopulation between sensitive and } \\
\text { resistant } \\
\text { sensitive (I-intermediate) }\end{array}$ \\
Resistant (R-resistant) & $\geq 19$ & Has resistance mechanisms \\
\hline
\end{tabular}

A four-dose version of the nutrient agar diffusion method was used to assess the reliability of antibiotic activity values according to the methodology [31].

At the same time, standard disks impregnated with different doses of antibiotic solutions were introduced into Petri dishes with the following concentrations: $2 \mathrm{mg} / \mathrm{dm}^{3}$, $4 \mathrm{mg} / \mathrm{dm}^{3}, 6 \mathrm{mg} / \mathrm{dm}^{3}$, and $8 \mathrm{mg} / \mathrm{dm}^{3}$.

For the study, we used a broad-spectrum antibiotic which is widespread in its useamoxiclav. Its active ingredient, amoxicillin, which is a semisynthetic penicillin ( $\beta$-lactam antibiotic), inhibits one or more enzymes during the biosynthetic metabolism of bacterial peptidoglycan. Inhibition of peptidoglycan synthesis leads to the weakening of the cell wall, resulting in lysis and cell death [32].

There are two mechanisms of resistance to amoxicillin/clavulanic acid:

- Inactivation by bacterial $\beta$-lactamases that are not themselves inhibited by clavulanic acid, including classes $\mathrm{B}, \mathrm{C}$, and $\mathrm{D}$;

- Bacterial impermeability or the reflux pump mechanism can cause or contribute to bacterial resistance, particularly in Gram-negative bacteria.

The resistance limit value $(\mathrm{R})$ was $>8 \mathrm{mg} / \mathrm{dm}^{3}$.

Biodiagnostics of the effect of surfactants on the tested activated sludge was carried out at the following basic indicators: COD $550 \mathrm{mg} / \mathrm{dm}^{3}$, with the surfactant at concentrations of 10,30 , and $50 \mathrm{mg} / \mathrm{dm}^{3}$, and a mandatory evaluation of the initial condition of the bioagent. The initial conditions were without a surfactant. We studied the effect of a nonionic surfactant-polyethylene oxide.

To obtain correct and reliable information, microbiological studies were carried out in 3 repetitions, with an exposure time of $16 \mathrm{~h}$.

Live preparations for the study of motility were prepared using the crushed drop method; morphological features and cell wall type were also studied on permanent preparations with Gram staining [33].

\section{Results and Discussion}

\subsection{Investigation of Purification of Wastewater from Nitrogen Compounds Using AOPS}

The water treatment quality results using AOPs are shown in Figure 5; these are quite consistent with the results obtained in previous studies using a combination of UV irradiation and the addition of hydrogen peroxide [23]. The comparison with these results 
is fair because, before reaching the photolysis unit, the aqueous solution passes through an electrolysis unit where, among other things, it is also saturated with hydrogen peroxide.

(a) Nitrate concentrations

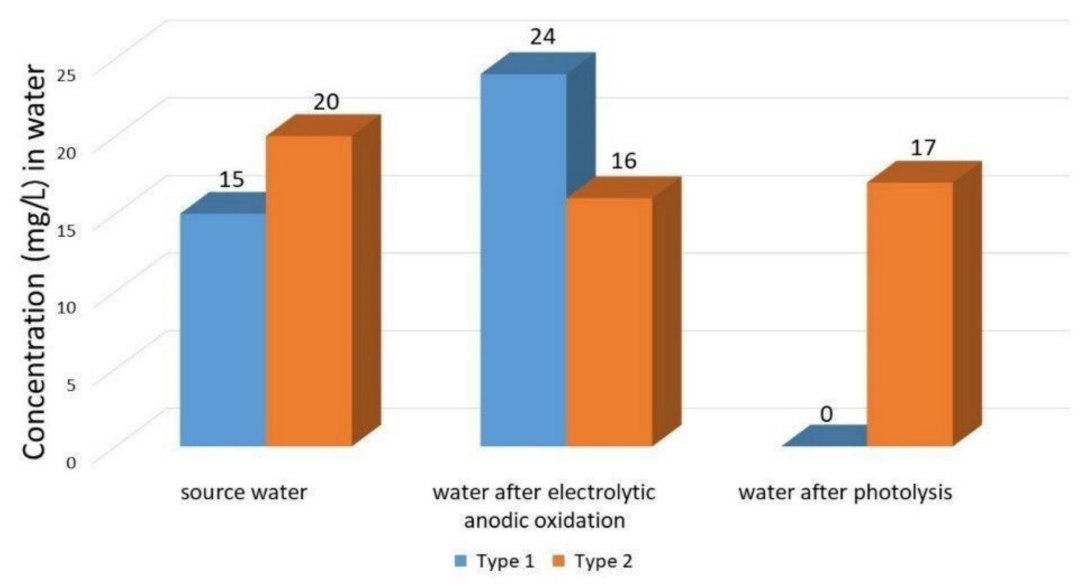

(b) Nitrite concentrations

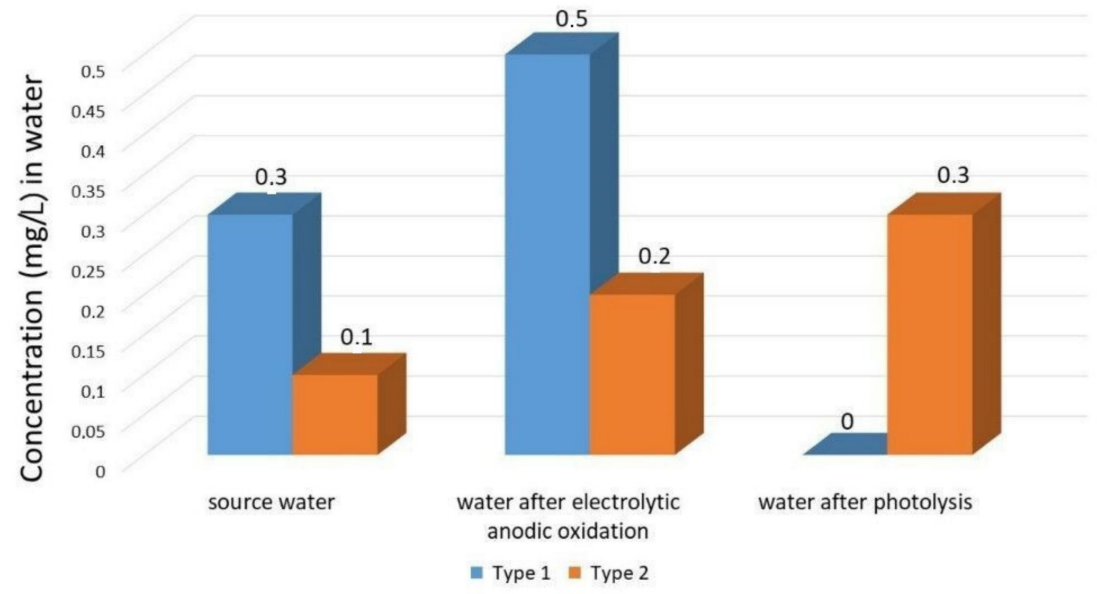

(c) Ammonium nitrogen concentration

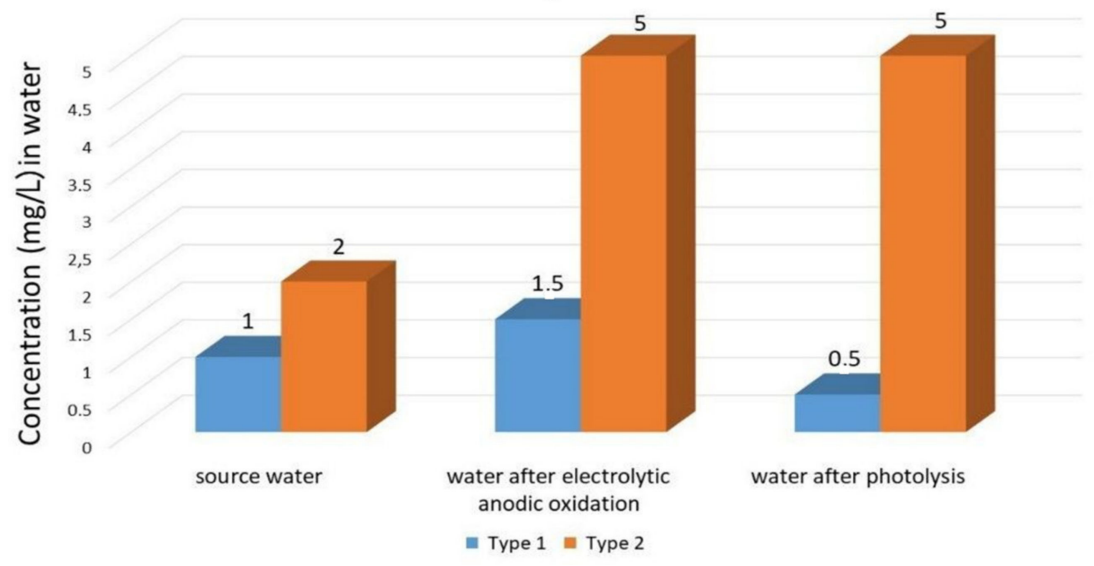

Figure 5. The results of experimental studies on the purification of wastewater from nitrogen compounds from CLWSI using AOPs.

At the same time, the increase in values of pollutants at the stage of anodic oxidation (on average by $59 \%$ ) should be noted: ammoniacal nitrogen by $50 \%$, nitrites by $67 \%$, and nitrates by $60 \%$. This can be explained by the process of oxidation of organic nitrogen (total nitrogen) along the chain "total nitrogen $\rightarrow$ ammonium nitrogen $\rightarrow$ nitrites $\rightarrow$ nitrates", 
and by the insufficient oxidative potential for the destruction of pollutants by anode oxidation alone.

Such conclusions are confirmed by the results of purification of the solution sampled $2 \mathrm{~h}$ after fish feeding, and its $1 \mathrm{x}$ turnover through the filter sieve and laminar settling tank. An improvement in the reduction of pollutants only by the indicator "nitrate concentration" was recorded: by $20 \%$ after anodic oxidation, and by $15 \%$ after photolysis. On the other hand, a negative result was obtained for ammoniacal nitrogen and nitrites (the situation worsened on average by $150 \%$ for all of the processes) - an increase in the concentration of pollutants. The concentration of ammoniacal nitrogen increased by $150 \%$ after anodic oxidation and photolysis; nitrite concentration increased after anodic oxidation by $100 \%$, and after photolysis by $200 \%$. The presented results are consistent with the findings of [34]. It can be reasonably assumed that the deterioration of the cleaning effect was caused by the excessive presence of organic pollutants—primarily organic (total) nitrogen-compared to the complex oxidative potential of the system "anodic oxidation + photolysis". In this case, the term "complex oxidative potential" implies not only the process of pollutant destruction itself, but also all accompanying and critically necessary physical and chemical processes.

Accordingly, the experimental studies (Figure 6) fully confirmed the preliminary conclusions about the blocking of oxidant synthesis by organic pollutants, their transportation to the necessary reaction zones, and their effective use.

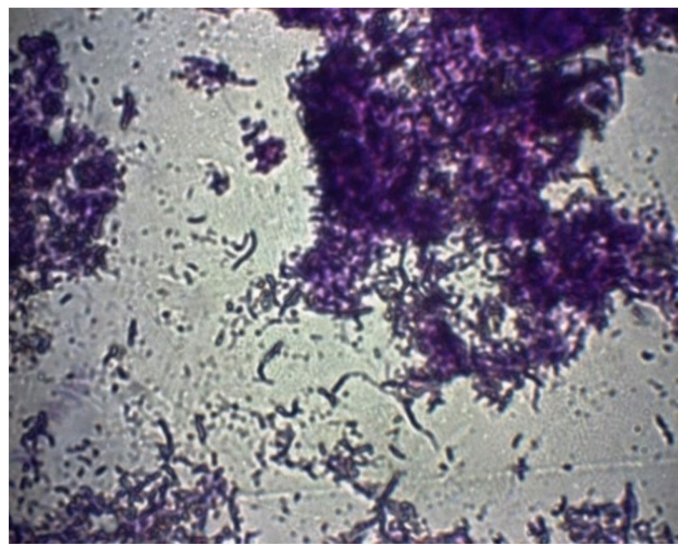

(a)

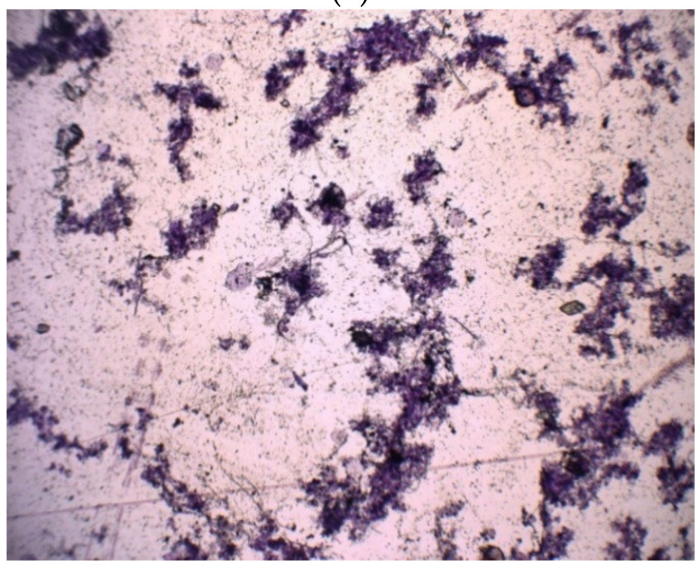

(c)

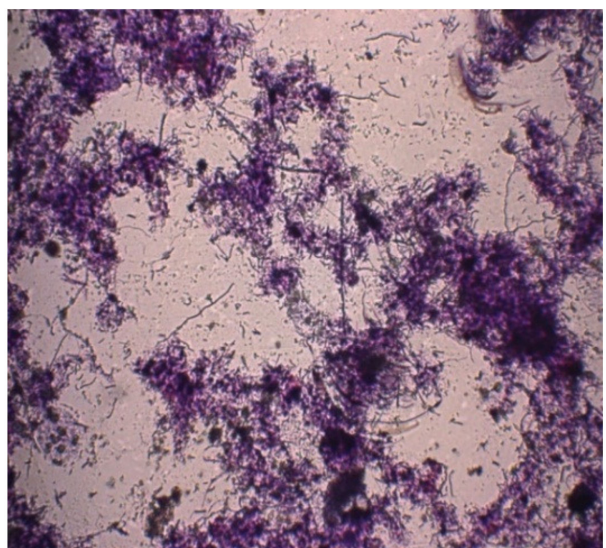

(b)

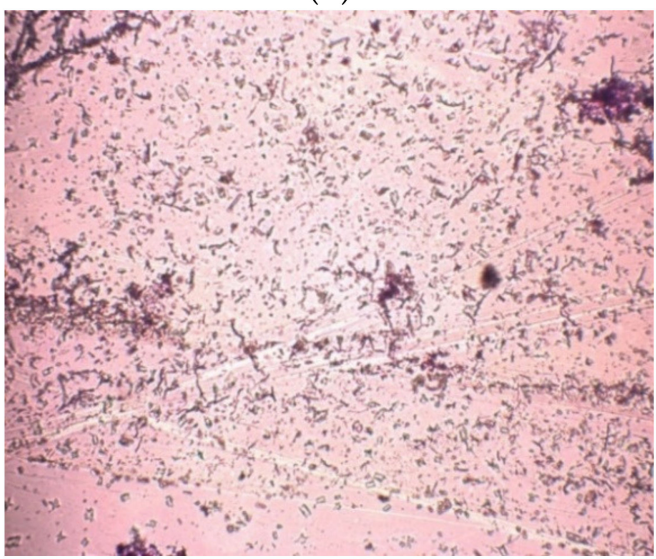

(d)

Figure 6. Deflocculation of activated sludge flakes when adding a sludge mixture with non-ionic surfactant at different concentrations, per gram, magnification $\times 40$ : (a) —control; (b) —surfactant $=$ $10 \mathrm{mg} / \mathrm{dm}^{3} ;(\mathbf{c})$-surfactant $=30 \mathrm{mg} / \mathrm{dm}^{3} ;(\mathbf{d})$-surfactant $=50 \mathrm{mg} / \mathrm{dm}^{3}$. 
At the same time, based on the experimental evaluation of the action of AOPs on nitrogenous pollutants, the need to combine oxidative processes with other methods of water treatment-for example, based on biological approaches-is fully confirmed.

\subsection{Modeling the Effects of Antibiotics and Surfactants on the Activity of Bioprocesses}

Based on the obtained quantitative data, the diagram in Figure 7 shows the diameter of the antibiotic growth suppression zone.

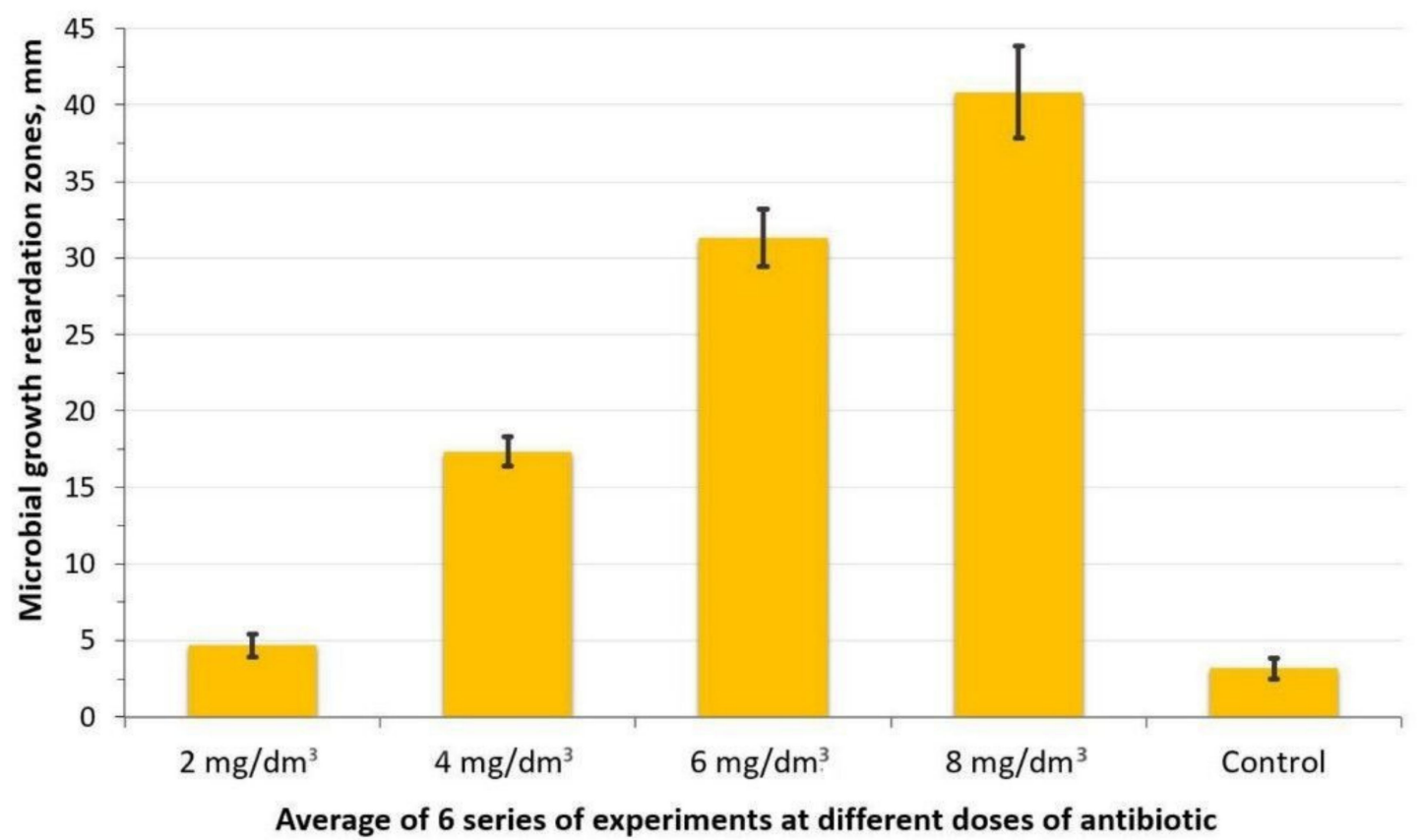

Figure 7. Interpretation of the results of determining the sensitivity of the storage culture of activated sewage sludge.

In in vitro experiments in all Petri dishes, we observed the same pattern. The value diameter of the growth retardation of the standard disk with amoxiclav by the accumulative culture of activated sludge was $17.3 \pm 2 \mathrm{~mm}$ at a concentration of $4 \mathrm{mg} / \mathrm{dm}^{3}$ (I), and $31.3 \pm 3 \mathrm{~mm}$ at a concentration of $6 \mathrm{mg} / \mathrm{dm}^{3}(\mathrm{~S})$. The mean growth retardation when cultured with an antibiotic concentration of $2 \mathrm{mg} / \mathrm{dm}^{3}$ and without antibiotic was $4.7 \pm 2 \mathrm{~mm}$ and $3.2 \pm 2 \mathrm{~mm}(\mathrm{R})$, respectively, which shows the insensitivity of the accumulative activated sludge culture to low concentrations of this antibiotic. The zone of stunting around the disc with amoxiclav at a maximum dose of $8 \mathrm{mg} / \mathrm{dm}^{3}$ was the largest in all dishes, and was $40.8 \pm 5 \mathrm{~mm}$ (S).

To distinguish between the three categories of sensitivity (or resistance), the so-called breakpoint concentrations of the antibiotic (or borderline values of the diameter of the zone of microbial growth suppression) are used.

During the first $24 \mathrm{~h}$, colonies began to grow; by the fourth day, colonies filled almost the entire surface of the growth medium, except for circles of different diameters around several standard disks with different antibiotic doses.

It is worth noting that the maximum bactericidal concentrations (MBCs) are not fixed values. They can be revised, depending on changes in the sensitivity of the microbial population in the activated sludge's biocenosis, which is consistent with previous studies [14,16].

The high duration of inhibition of the active biomass in the presence of non-ionogenic surfactant should be noted. At almost all concentrations studied-even at the minimum concentration of $10 \mathrm{mg} / \mathrm{dm}^{3}$ - the activated sludge was not completely recovered, which was expressed in a decrease in its quantity and in the inability to aggregate flakes of activated sludge at the end of the indication process $(16 \mathrm{~h})$ compared to the initial content (Figure 8). 


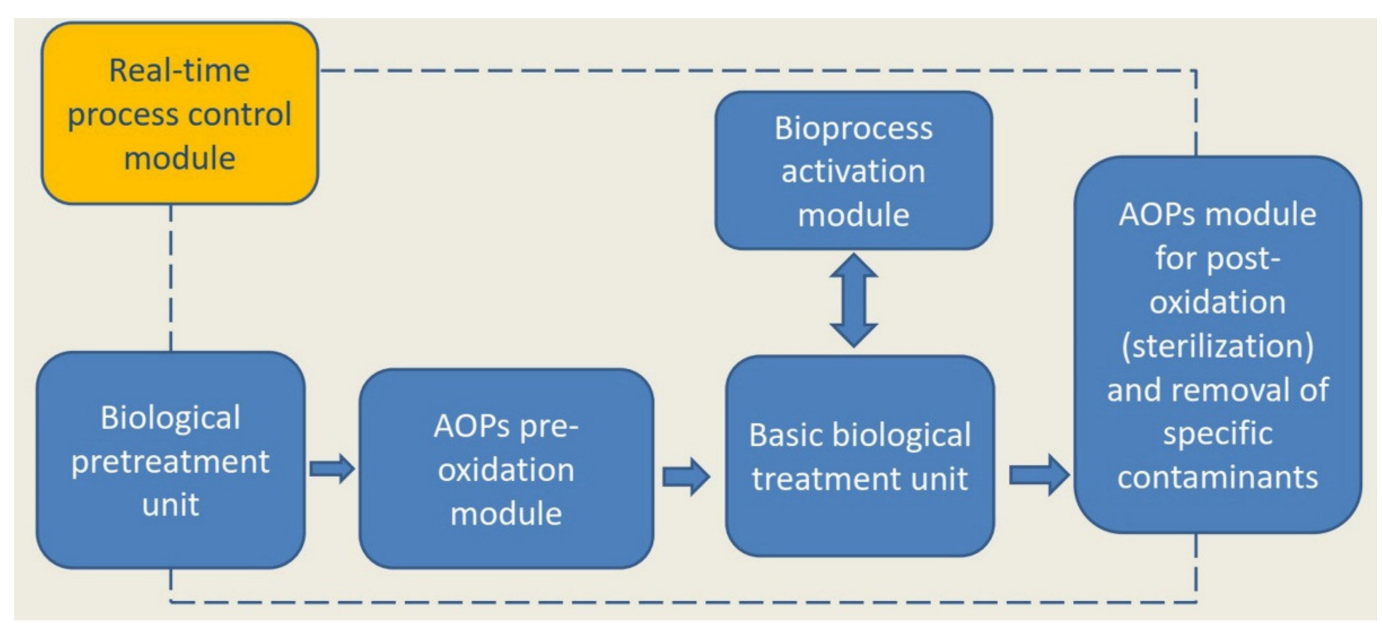

Figure 8. Systemic combination of biological processes and AOPs in wastewater treatment (averaging devices, sand traps, and other pretreatment elements are not specified).

Increasing the concentration of surfactants significantly worsened the condition of the mixed population of microorganisms, as evidenced by the process of deflocculation of activated sludge observed by visual inspection using light microscopy (Figure 7). The recovery potential of activated sludge at the end of the biological wastewater treatment process was significantly influenced by its initial condition, indicating the need for the long-term regeneration of impaired activated sludge, as confirmed in several previous studies $[5,19]$.

Thus, the results of this experiment cannot be accepted as positive, even at a surfactant concentration of $10 \mathrm{mg} / \mathrm{dm}^{3}$. This has a negative effect, which may be associated with structural changes in the qualitative composition of the microbiocenosis, leading to a decrease in species diversity, which confirms the results of previous studies $[5,6,20]$. A well-functioning activated sludge system always depends on a wide range of species within it, which has also been noted in [19]. When exposed to various unfavorable factors, there is a high probability that overly sensitive and less adapted species will leave the given community, and that their ecological niches will be occupied by the most adapted species and, as a whole, the community can continue its existence. However, from a practical point of view, considering the activated sludge's biocenosis as a biological system of wastewater treatment for various kinds of pollutants, such shifts in species composition will negatively affect the processes of removing a wide range of substances and water treatment in general, as confirmed in previous studies $[5,13,19,35]$.

\subsection{Development of an Integrated Model for Combining Biological Processes and AOPs in Wastewater Treatment}

In Table 2, we list the main technological disadvantages for the systems of physical (mechanical), chemical, and biological methods of purification.

As can be seen from Table 2, the physical methods include filtration, centrifugation, ultrasound, ozonation, etc., while the chemical methods include the use of various reagents, realization of processes of coagulation, flocculation, chlorination, etc. Thus, in the very principles of their implementation, AOPs, in a broad sense, are a set of chemical treatment procedures designed to remove organic (and sometimes inorganic) materials from water and wastewater. However, in actual wastewater treatment applications, the term usually refers more specifically to a subset of such chemical processes that use ozone $\left(\mathrm{O}_{3}\right)$, hydrogen peroxide $\left(\mathrm{H}_{2} \mathrm{O}_{2}\right)$, and/or UV light. One of these types of processes is called in situ chemical oxidation. 
Table 2. Types of technological disadvantages according to different methods of wastewater treatment.

Disadvantages of Physical (Mechanical) Methods

- $\quad$ Possibility of creation, as a result of partial clogging of filtering elements, of bacterial colonies on operating water treatment facilities (filters);

- Accumulation of filtered masses harmful to both people and the environment (filters, centrifuges, settling tanks, hydrocyclones);

- $\quad$ Exclusively continuous flow-through operation (filters, centrifuges, hydrocyclones);

- Destruction only of viruses, microbes, and bacteria themselves, and not of their more harmful products (ultrasound, irradiation, ozonation);

- Destruction of useful (necessary for humans) microflora (ultrasound, ozonation, irradiation);

- Limited aftereffect and penetration at high concentrations of pollutant (ozonation, irradiation, ultrasound).

\section{Disadvantages of Chemical Methods}

- The possible formation of new compounds as a result of chemical reactions that are more harmful to humans and the environment than the original pollutants (all methods);

- Accumulation of a large volume of harmful "used reagent + pollutant" complexes (coagulation, flocculation);

- Destruction of useful microflora (chlorination);

- $\quad$ Presence of a reagent farm, which is itself a pollutant (all methods).

\section{Disadvantages of Biological Methods}

- High requirements for compliance with technological and regime parameters of bioprocesses (temperature, pressure, ORP, incoming water composition, frequency of additional nutrients, hydraulic retention time of activated sludge); significant energy costs or possible deterioration of treatment efficiency (all methods);

- Low level of adaptation to the existing "salvo" releases of chemically active harmful substances (all methods);

- Greater complexity and cost of intensification (acceleration) of purification processes (vermiculture, biological ponds).

From the technological point of view, the development of new methods of using water treatment and water purification technologies is prompted by their known operational drawbacks, which have been investigated in several works $[10,11,13,19]$.

It is worth noting that a common disadvantage of these methods is that dozens of water quality and process parameters must be monitored in real time, and only a few automated measuring devices exist and work reliably at industrial facilities. It is necessary to take into account the qualitative and quantitative parameters of the operation of the activated sludge biosystem in order to form a dynamic equilibrium in its species diversity for the most effective destruction of organic pollutants.

Thus, a promising direction is the use of methodological approaches of aggregation of different basic approaches to water treatment. For example, the analysis of industrial systems, in the case of a combination of basic methods (necessary for the treatment of industrial effluents), showed the overlapping effect of different equipment on the same pollutants: the cross-effect of different methods on one type of pollutant varies from 5 to $40 \%$ [7]. Based on the results obtained, the sequence of creating water treatment systems with enhanced functionality, and their ability to effectively counteract emergencies, the method of combining solutions for removing pollutants from effluents is justified [36,37].

For an example of a combination of different basic solutions, consider the use of biological processes as the technological core, while reducing their disadvantages with AOPs.

Ozone, chlorine, sodium hypochlorite, hydrogen peroxide, and Fenton's reagent are the most commonly used oxidants. Each of these reagents has its advantages and 
disadvantages, so the introduction of advanced oxidative processes in the practice of water treatment together with other methods also seems very relevant.

The basic advantage of biological treatment methods is their environmental friendliness and safety for the natural components of the environment. Difficulties manifest themselves in the stabilization and formation of an equilibrium system between the processes of decomposition of complex organic impurities and preservation of the constancy of the biomass of the necessary ecological and trophic groups of microorganisms. It is important to stimulate the development of the desired dominant species composition of activated sludge, increasing their metabolic activity, which is possible with the use of physical and chemical methods of activation of biological processes [36].

Inhibitors of biological processes used in wastewater treatment plants, which can be eliminated by using AOPs, can include the entry of surfactants and antibiotics with effluents. Thus, surfactants impair the sedimentation of wastewater and inhibit oxygen transport to the cells of activated sludge microorganisms in aeration tanks. Increasing concentrations of antibiotics in wastewater submitted for treatment inhibits the growth of activated sludge microorganisms; under anaerobic conditions, the productivity of the biosystem falls, biogas yield decreases, and incomplete denitrification with an increase in residual pollution occurs. This also affects the composition of the sewage sludge from the wastewater treatment plant, which is further stockpiled on sludge cards, and is not utilized due to increased pollutant contamination [36,38].

Disadvantages of AOPs neutralized by biochemical solutions include:

- Blocking organic pollutants from synthesizing oxidants, transporting them to the necessary reaction zones;

- $\quad$ Reduction of oxidation efficiency;

- Use of active oxidants to remove pollutants, which are also eliminated by cheaper and simpler solutions.

To substantiate these directions of combinations of cleaning methods in order to level the disadvantages of AOPs using biochemical solutions, experiments on the treatment of aqueous solution circulating in a closed-loop water supply plant for industrial fish farming were conducted.

Based on the above-mentioned purposes of combined use, a scheme of water treatment is proposed (Figure 8).

Consider in more detail each of the treatment units shown in Figure 8:

- Pre-biological treatment unit (aerobic filtration): removal (partial) of pollutants that passivate AOPs' oxidation processes (reduce efficiency); biochemical "start-up" of redox processes;

- $\quad$ Pre-oxidation module (pressurized electrolysis, anolyte generation, chlorine-derived oxidizers): direct oxidation of pollutants, formation of pollutant complexes for more effective biological removal, elimination of surfactants, and partial elimination of antibiotics;

- Block of the main biological treatment (anaerobic denitrification stage): NOx reduction to gaseous nitrogen in the process of activity of heterotrophic denitrifying bacteria, with the formation of anoxic zones in the activated sludge flocculus against the background of anaerobiosis of the biosystem as a whole;

- Biological processes activation module (electrolysis activation units, hydro- and ultrasonic cavitators, electromagnetic irradiators): intensification of biological processes of water treatment at the stage of dephosphatation under biochemical sulfate reduction with precipitation of heavy metals;

- AOPs pre-oxidation (sterilization) and removal of specific pollutants (photo-isolation, Fenton reaction, pressurized electrolysis, electrokinetic oxidation) module: final elimination of pollutants of aqueous solutions submitted to oxidation (reduction), including SPAs and antibiotics. 
The process-control module in real time: management and coordination of minimumreagent combination of biological processes and AOPs for wastewater treatment in real time (by indicators: $\mathrm{pH}, \mathrm{COD}$, turbidity, ORP, silt index, conductivity, and temperature).

Using such a system (Figure 8), it is possible to apply the elements of inorganic pollutant removal, $\mathrm{pH}$ correction, and other necessary solutions.

In Figure 9 we have formalized the flows of the combined wastewater treatment system with the identification of several control parameters, grouping them into two blocks:

1. The basic parameters of control on the characteristic influence factors of the input wastewater;

2. Control indicators of the biological system, which take into account the state of the biocenosis of activated sludge when affecting the basic parameters of control.

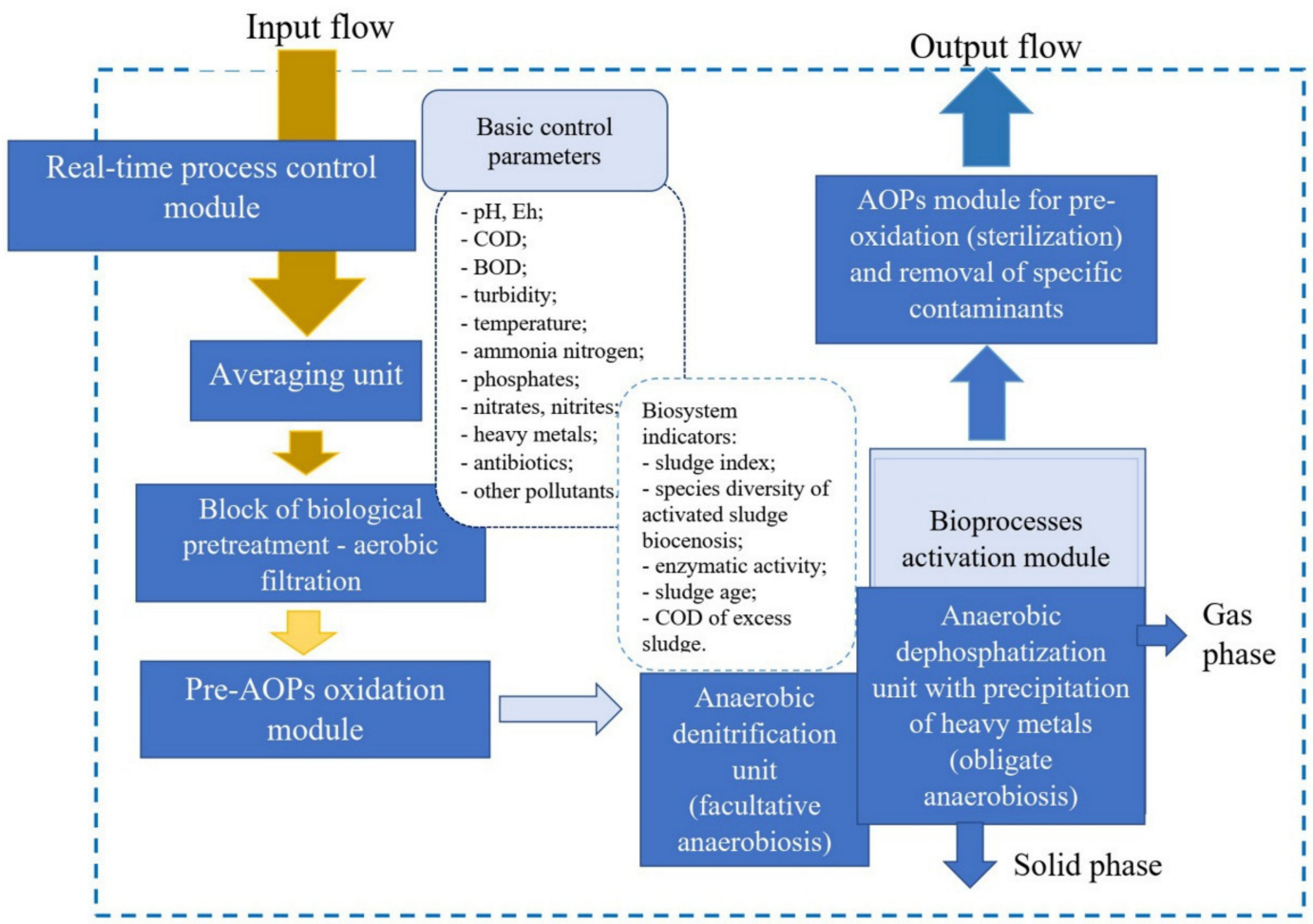

Figure 9. Integrated formalized model of the combination of biological processes and AOPs in wastewater treatment.

It is important to note that the categorical parameters of biosystem state control-i.e., forming a response to the parameters of basic control-have a "mutual optimum" zone of intersection. Such a zone is understood as a range of values of the parameters of the biosystem in their combination. For example, the dependence of the sludge index on the dose of activated sludge when increasing its sedimentation rate-this maintains a high level of oxidation capacity of aeration tanks, determining the amount of contaminants that can be oxidized by microbial biocenosis inhabiting a certain volume of activated sludge or biofilm for 1 day. In this case, the oxidative capacity of biological treatment facilities depends on the oxygen supply of microorganisms of different ecological and trophic groups of activated sludge, and on directional change in the chemical activity of microorganisms along the trophic chains. In the thermophilic mode, the oxidative capacity of sewage treatment plants is increased by 1.5-2 times, but this mode is more energy-consuming than the mesophilic one.

Thus, we assume the possibility of determining the integral function of the biosystem through the weight coefficients of the main indicators of its activity-namely, the age of sludge (days), silt index $(\mathrm{mL} / \mathrm{g})$, silt dose $(\mathrm{g} / \mathrm{L})$, the number of silt bioceno- 
sis species, the percentage ratio of the number of microorganisms by trophic groups (cellulolytes/hydrolytes, mineralizators, oligonitrophils, ammonificators, oligotrophs) $\left(\mathrm{CFU} \cdot 10^{5} / \mathrm{mL}\right.$ ), and enzymatic activity (by catalase) $\left(\mathrm{mg} / \mathrm{dm}^{3}\right)$. Further research will focus on the modeling of such a function, with the justification of its application to improve the efficiency of sewage treatment plants.

\section{Conclusions}

The main technological disadvantages of the systems of physical (mechanical), chemi$\mathrm{cal}$, and biological methods of treatment were grouped into a single block diagram. It was highlighted that a common disadvantage of the methods is that it is necessary to monitor dozens of parameters of water quality and technological processes in real time, and there is a limited number of automated measuring devices that work reliably at industrial sites. It is also necessary to consider qualitative and quantitative parameters of the operation of the activated sludge biosystem in order to form a dynamic equilibrium in its species diversity for the most effective destruction of organic pollutants. Thus, a promising direction is the use of methodical approaches of the aggregation of different basic approaches to water treatment. As an example of a combination of different basic solutions, the use of biological processes as a technological core was considered, while reducing their disadvantages with the help of AOPs.

Studies were conducted on water treatment using an electric process pilot plant to remove contaminants from the circulating water of fish farming equipment. It was determined that the deterioration of the treatment effect was due to the excessive presence of organic pollutants-primarily organic (total) nitrogen-compared to the complex oxidative potential of the system of "anodic oxidation + photolysis". This can be explained by the process of oxidation of organic nitrogen (total nitrogen) along the chain "total nitrogen $\rightarrow$ ammonium nitrogen $\rightarrow$ nitrites $\rightarrow$ nitrates", and by the insufficient oxidative potential of the destruction of pollutants by anode oxidation alone.

In an in vitro microbiological study to assess the resistance of the biocenosis to an antibiotic such as amoxiclav, we observed the same pattern. Thus, the value of the stunting diameter of the accumulating activated sludge culture when cultured with an antibiotic concentration of $2 \mathrm{mg} / \mathrm{dm}^{3}$ and without the antibiotic was $4.7 \pm 2 \mathrm{~mm}$ and $3.2 \pm 2 \mathrm{~mm}$ ( $\mathrm{R}$-resistant), respectively, which shows the insensitivity of the accumulated activated sludge culture to low concentrations of this antibiotic. The stunting zone around the amoxiclav disk with a maximum dose of $8 \mathrm{mg} / \mathrm{dm}^{3}$ was the largest in all dishes, and was $40.8 \pm 5 \mathrm{~mm}$ (S-sensitive). The results of bioindication of activated sludge cannot be taken as positive- even at the surfactant concentration of $10 \mathrm{mg} / \mathrm{dm}^{3}$, which is still negative-which can be attributed to structural changes in the qualitative composition of the microbiocenosis, leading to a narrowing of species diversity.

To implement the combined processes of biological treatment and AOPs, formalization of the main functional elements of the system, in terms of comprehensive elimination of the drawbacks of individual technological solutions of water treatment, and increasing their effectiveness, was carried out. The proposed combination of wastewater treatment methods can potentially be used for the treatment of wastewater from various industrial facilities with multicomponent pollutants of organic and inorganic nature:

- Food enterprises (dairies, meat processing plants, fish processing, winemaking, cheese factories);

- $\quad$ Agro-industrial complexes (poultry farms, livestock farms, pig farms);

- Light industry (wood processing, tanneries, cosmetology);

- Communal objects.

Author Contributions: Conceptualization, methodology, and writing - original draft preparation, V.S. and Y.C.; experiment performance and data analysis, V.S. and Y.C.; conceptualization, validation, writing—-review and editing, and funding acquisition, M.B.; formal analysis and technical support, 
S.D. and V.C.; writing-review, M.G. All authors have read and agreed to the published version of the manuscript.

Funding: This research was funded by VEGA-Scientific Grant Agency of the Ministry of Education, Science, Research, and Sport of the Slovak Republic and the Slovak Academy of Sciences, grant number 1/0419/19.

Institutional Review Board Statement: Not applicable.

Informed Consent Statement: Not applicable.

Acknowledgments: This research project was carried out as planned research projects of the International Innovation and Applied Center "Aquatic Artery" based on Department of Ecology and Environmental Protection Technologies, Sumy State University and connected with the project "Reduction of technogenic loading on the environment of enterprises of chemical, machine-building industry, and heat and power engineering" according to the scientific and technical program of the Ministry of Education and Science of Ukraine (state registration No 0116U006606).

Conflicts of Interest: The authors declare no conflict of interest.

\section{References}

1. Bao, Y.; Li, F.; Chen, L.; Mu, Q.; Huang, B.; Wen, D. Fate of antibiotics in engineered wastewater systems and receiving water environment: A case study on the coast of Hangzhou Bay, China. Sci. Total Environ. 2021, 769, 144642. [CrossRef]

2. Gnida, A.; Felis, E.; Ziembińska-Buczyńska, A.; Łuczkiewicz, A.; Surmacz-Górska, J.; Olańczuk-Neyman, K. Evidence of mutations conferring resistance to clarithromycin in wastewater and activated sludge. 3 Biotech 2020, 10, 1-11. [CrossRef]

3. Vasenko, O.; Zinchenko, I.; Tsytlishvili, K.; Bikasov, V. Research methods of inactivation of the antibiotic cyprofloxacin to prevent environmental pollution and protect human health. Sci. Horiz. 2020, 7, 19-25. [CrossRef]

4. Pavolová, H.; Lacko, R.; Hajduová, Z.; Šimková, Z.; Rovňák, M. The Circular Model in Disposal with Municipal Waste. A Case Study of Slovakia. Int. J. Environ. Res. Public Health 2020, 17, 1839. [CrossRef] [PubMed]

5. Corada-Fernandez, C.; Jimenez-Martinez, J.; Candela, L.; Mazo, E.G. Presence of synthetic surfactants in groundwater derived by sewage contamination. Eur. Geosci. Union Gen. Assem. 2011, 13, EGU2011-EGU4966.

6. Balymova, E.S.; Zakirov, R.K.; Gaynetdinova, R.R.; Akhmadullina, F.Y. Biadiagnostics of activated sludge as a method for rapid control of wastwater biological treatment. Bezop. V Tekhnosfere 2012, 4, 11-17.

7. Shtepa, V.M.; Goncharov, F.I.; Syrovotka, M.А. Обгрунтування та розробка критерію енергоефективності функціонування електротехнологічних систем водопідготовки[Rationale and development of energy efficiency criteria for operation of electrical process water treatment systems]. Sci. Her. NULES Ukraine. Ser. Mach. Energ. 2011, 161, 187-193.

8. Shtepa, V.M. Обгрунтування робочої міри ефективності електротехнологічної водоочистки[Rationale for a working measure of the efficiency of electro-technological water treatment]. Energy Autom. 2018, 4, 99-111. [CrossRef]

9. Vertai, S.P.; Shtepa, V.M. Обоснование структуры и заданий системы поддержки принятия решенийобобщённойоценки перспективности инновационных технологий[Rationale for the structure and tasks of the decision support system of the generalized assessment of the prospects of innovative technologies]. Sci. Her. NULES Ukraine. Ser. Mach. Energetics 2016, 240, 86-93.

10. Topalić Marković, J.; Mučenski, V.; Savić, D.; Velkovski, T.; Peško, I.; Tomaš, L. Risk assessment model for planning and design processes of wastewater treatment plants. Period. Polytech. Civ. Eng. 2021, 65, 181-190.

11. Ownby, M.; Desrosiers, D.-A.; Vaneeckhaute, C. Phosphorus removal and recovery from wastewater via hybrid ion exchange nanotechnology: A study on sustainable regeneration chemistries. NPJ Clean Water 2021, 4, 1-8. [CrossRef]

12. Jiang, X.; Wang, H.; Wu, P.; Wang, H.; Deng, L.; Wang, W. Nitrification performance evaluation of activated sludge under high potassium ion stress during high-ammonia nitrogen organic wastewater treatment. J. Environ. Sci. 2022, 111, 84-92. [CrossRef]

13. Zhang, J.; Shao, Y.; Liu, G.; Qi, L.; Wang, H.; Xu, X.; Liu, S. Wastewater COD characterization: RBCOD and SBCOD characterization analysis methods. Sci. Rep. 2021, 11, 1-10.

14. Qiu, G.; Chen, H.; Raghavan, D.S.S.; Ting, Y.P. Removal behaviors of antibiotics in a hybrid microfiltration-forward osmotic membrane bioreactor for real municipal wastewater treatment. Chem. Eng. J. 2021, 417, 129146. [CrossRef]

15. Shi, Y.-J.; Yang, L.; Liao, S.-F.; Zhang, L.-G.; Liao, Z.-C.; Lan, M.-Y.; Sun, F.; Ying, G.-G. Responses of aerobic granular sludge to fluoroquinolones: Microbial community variations, and antibiotic resistance genes. J. Hazard. Mater. 2021, 414, 125527. [CrossRef]

16. Zhu, T.T.; Su, Z.X.; Lai, W.X.; Zhang, Y.B.; Liu, Y.W. Insights into the fate and removal of antibiotics and antibiotic resistance genes using biological wastewater treatment technology (Review). Sci. Total Environ. 2021, 776, 145906. [CrossRef]

17. Siedlecka, A.; Wolf-Baca, M.; Piekarska, K. Microbial communities of biofilms developed in a chlorinated drinking water distribution system: A field study of antibiotic resistance and biodiversity. Sci. Total Environ. 2021, 774, 145113. [CrossRef] [PubMed] 
18. Shi, L.; Hu, Z.; Wang, Y.; Bei, E.; Lens, P.N.; Thomas, O.; Hu, Y.; Chen, C.; Zhan, X. In Situ electrochemical oxidation in electrodialysis for antibiotics removal during nutrient recovery from pig manure digestate. Chem. Eng. J. 2021, $413,127485$. [CrossRef]

19. Kruszelnicka, I.; Ginter-Kramarczyk, D.; Wyrwas, B.; Idkowiak, J. Evaluation of surfactant removal efficiency in selected domestic wastewater treatment plants in Poland. J. Env. Health Sci. Eng. 2019, 17, 1257-1264. [CrossRef] [PubMed]

20. Dereszewska, A.; Cytawa, S.; Tomczak-Wandzel, R.; Medrzycka, K. The Effect of Anionic Surfactant Concentration on Activated Sludge Condition and Phosphate Release in Biological Treatment Plant. Pol. J. Environ. Stud. 2015, 24, 83-91. [CrossRef]

21. Stasinakis, A.S. Use of selected advanced oxidation processes (AOPs) for wastewater treatment-a mini review. Glob. NEST J. 2008, 10, 376-385.

22. Costa, E.P.; Roccamante, M.; Amorim, C.C.; Oller, I.; Pérez, J.A.S.; Malato, S. New trend on open solar photoreactors to treat micropollutants by photo-Fenton at circumneutral pH: Increasing optical pathway. Chem. Eng. J. 2020, 385, 123982. [CrossRef]

23. Malvestiti, J.A.; Dantas, R.F. Influence of industrial contamination in municipal secondary effluent disinfection by UV/H2O2. Environ. Sci. Pollut. Res. 2019, 26, 13286-13298. [CrossRef]

24. Homonnay, Z. Characterization of FeVI and Other Oxidation States of Iron by Spectroscopic Methods. In Proceedings of the International Symposium, Prague, Czech Republic, 31 May 2020; pp. 55-63.

25. Ali, Z.; Ahmad, R. Nanotechnology for Water Treatment. In Environmental Nanotechnology; Dasgupta, N., Ranjan, S., Lichtfouse, E., Eds.; Springer: Cham, Switzerland, 2020; Volume 3. [CrossRef]

26. Wu, J.; Xue, S.; Bridges, D.; Yu, Y.; Zhang, L.; Pooran, J.; Hill, C.; Wu, J.; Hu, A. E-based ceramic nanocomposite membranes fabricated via e-spinning and vacuum filtration for $\mathrm{Cd}^{2+}$ ions removal. Chemosphere 2019, 230, 527-535. [CrossRef] [PubMed]

27. Saaremäe, E.; Liira, M.; Poolakese, M.; Tamm, T. Removing phosphorus with Ca-Fe oxide granules-A possible wetlands filter material. Hydrol. Res. 2014, 45, 368-378. [CrossRef]

28. Muszynski, A.; Marcinowski, P.; Maksymiec, J.; Beskowska, K.; Kalwarczyk, E.; Bogacki, J. Cosmetic wastewater treatment with combined light $/ \mathrm{Fe}^{0} / \mathrm{H}_{2} \mathrm{O}_{2}$ process coupled with activated sludge. J. Hazard. Mater. 2019, 378, 120732. [CrossRef]

29. Lurie, Y. Unified methods of water analysis. In Chemistry, 2nd ed.; Hydrometeoizdat: Moskow, Russia, 1973.

30. Ministry of Health of the Russian Federation. Determination of the Antimicrobial Activity of Antibiotics by Diffusion in Agar. 2007. Available online: https:/ / docs.cntd.ru/document/420324586 (accessed on 7 March 2021).

31. Gribbs, D.L. Antibiotic Potency Assay as Described in USP Chapter (81). Pharm. Microbiol. Forum Newsl. 2008, 14, 2-15.

32. Compendium Medicines. Available online: https://compendium.com.ua/info/135608/amoksiklav-sup-sup-/ (accessed on 9 March 2021).

33. Ahern, H. Microbiology: A Laboratory Experience. State University of New York at Geneseo. 2018. Available online: https: // milnepublishing.geneseo.edu/suny-microbiology-lab/chapter/differential-staining-techniques/ (accessed on 1 March 2021).

34. Rahmadi, P.; Kim, Y.R. Effects of different levels of ozone on ammonia, nitrite, nitrate, and dissolved organic carbon in sterilization of seawater. Desalination Water Treat. 2014, 52, 4413-4422. [CrossRef]

35. Wiest, L.; Gosset, A.; Fildier, A.; Libert, C.; Hervé, M.; Sibeud, E.; Giroud, B.; Vulliet, E.; Bastide, T.; Polomé, P.; et al. Occurrence and removal of emerging pollutants in urban sewage treatment plants using LC-QToF-MS suspect screening and quantification. Sci. Total Environ. 2021, 774, 145779. [CrossRef]

36. Chernysh, Y.; Balintova, M.; Plyatsuk, L.; Holub, M.; Demcak, S. The influence of phosphogypsum addition on phosphorus release in biochemical treatment of sewage sludge. Int. J. Environ. Res. Public Health 2018, 15, 1269. [CrossRef]

37. Plyatsuk, L.; Balintova, M.; Chernysh, Y.; Demcak, S.; Holub, M.; Yakhnenko, E. Influence of Phosphogypsum Dump on the Soil Ecosystem in the Sumy region (Ukraine). Appl. Sci. 2019, 9, 5559. [CrossRef]

38. Kim, Y.; Farnazo, D.M. Toxicity characteristics of sewage treatment effluents and potential contribution of micropollutant residuals. J. Ecol. Env. 2017, 41, 39. [CrossRef] 